\title{
Sistem Informasi Penjualan Alat Dan Barang Olahraga Pada Toko Ratu Sport Pematangsiantar
}

\section{Information System Sales Of Equipment And Sport Goods On Ratu Sport Shopping Party}

\author{
Rafiqa Dewi1)*, Iin Parlina1), Ahmad Revi2) ,Stefani Nadia Risky²) \\ 1)AMIK Tunas Bangsa Pematangsiantar, Indonesia \\ 2) Mahasiswa AMIK Tunas Bangsa Pematangsiantar, Indonesia
}

\begin{abstract}
*Coresponding Email: rafiqa@amiktunasbangsa.ac.id
Abstrak

Perancangan Sistem Informasi Penjualan Alat Dan Barang Olahraga Pada Toko Ratu Sport Pematangsiantar". Sistem ini dibuat untuk mengolah data, Pembeli, Karyawan, penjualan, Barang. Sistem ini dibuat menggunakan software Microsoft Visual Basic 6.0 dan database SQL Server 2000. Perancangan Sistem Informasi Penjualan ini dibangun menggunakan metode analisis yaitu mengolah data dengan menggunakan Data Flow Diagram, Entity Relatinship Diagram, dan FlowChart. Metode perancangan proses yang berfokus pada pengembangan model ini dapat menyelesaikan masalah redudansi data, kelambatan pencarian data, dan masalah pengolahan data.
\end{abstract}

Kata kunci : Microsoft Visual Basic 6.0, SQL Server 2000, Redudansi

\begin{abstract}
Sales Information System Design tools and sporting goods in shops queen sport Pematangsiantar". Singer system createdfor the review process the data, customer, supplier, sales and buying. The system is built by using Visual Basic 6.0 Software and SQL Server database. Purchasing Information System Sales And Singer built using method analysis that is a processing the data by using Data Flow Diagram, Entity Relationship Diagram and Flowchart, process design and method that focuses on the development of this model can solve the problam of data redudancy, slowness data retrieval, and data processing problems.
\end{abstract}

Keywords : Microsoft Visual Basic 6.0, SQL Server 2000, Redudancy

How to Cite: Dewi, R. Parlina, I. Revi, A. Risky, S,N. (2018). Sistem Informasi Penjualan Alat Dan Barang Olahraga Pada Toko Ratu Sport Pematangsiantar. JITE (Journal Of Informatics And Telecommunication Engineering). Vol (2). No (1): 48-51 


\section{PENDAHULUAN}

Toko Ratu Sport Pematangsiantar dalam proses pengolahan data penjualannya belum menggunakan sistem komputerisasi sehingga akan sulit untuk mengontrol ketersediaan alat dan barang olahraga yang habis atau masih ada.

Penjualan alat dan barang olah raga selama ini tidak terpantau antara barang yang keluar dan yang masuk pada saat terjadi transaksi penjualan atapun pengadaan barang sehingga pada saat alat atau barang olahraga tersebut dibutuhkan tidak tersedia dalam gudang.

Sistem informasi penjualan alat dan barang olah raga secara terkomputerisasi ini dapat mempermudah proses penjualan alat dan barang olah raga dan untuk mempermudah pegawai dalam mencari dokumen-dokumen untuk pencatatan setiap bulannya.

Dalam membangun sistem ini digunakan alat bantu pengembangan sistem informasi yaitu dengan menggunakan software Microsoft Visual Basic 6.0 dan SQL Server 2000.

\section{METODE PENELITIAN}

Lokasi Penelitian di Toko Ratu Sport Pematangsiantar.

Pengumpulan data dilakukan secara langsung dengan tatap muka antara remunator (pewawancara dengan responden dengan menggunakan pertanyaan-pertanyaan, dengan substansinya adalah perolehan jawaban responden, atas pertanyaan-pertanyaan yang diajukan untuk mendapatkan data primer mengenai persepsi dan permintaan responden terhadap sistem informasi penjualan alat dan barang olah raga.

\section{Rancangan Proses}

Adapun rancangan proses dari Sistem Informasi Penjualan alat dan barang olahraga ini digambarkan dengan diagram alir data atau dikenal sebagai DFD (Data Flow Diagram). Berikut ini merupakan gambaran rancangan proses dari Sistem Informasi Jumlah Pesanan Cetakan tersebut :

\section{Data Flow Diagram (DFD)}

DFD dalam proses perancangan database merupakan hal penting yang harus dilakukan, karena dengan melihat DFD maka kita akan mengetahui arus data yang mengalir dalam suatu sistem dan mengimplementasikannya pada pembuatan database secara fisik dengan menggunakan DBMS yang telah dipilih.

a). DFD Level 0

Pada DFD level 0, digambarkan bahwa pemakai sistem adalah User. User melakukan proses Sistem Informasi Jumlah Cetakan tersebut. Kemudian User 
mendapatkan output terakhir berupa informasi.

b). DFD level 1

DFD Level 1 Perancangan Sistem Informasi Penjualan alat dan barang olahraga Pada Toko Ratu Sport Pematangsiantar dapat dilihat pada gambar 2. di bawah ini

\section{HASIL DAN PEMBAHASAN}

\section{Form Merek}

Form Merek digunakan untuk mengolah data Merek, seperti pada gambar 1. berikut:

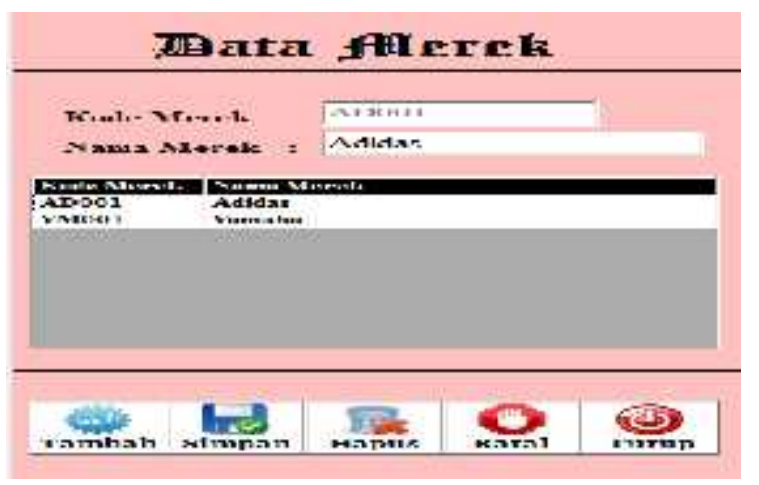

Gambar 1. Form Merek

\section{Form Barang}

Form Barang digunakan untuk mengolah data Barang, seperti pada gambar 2 berikut

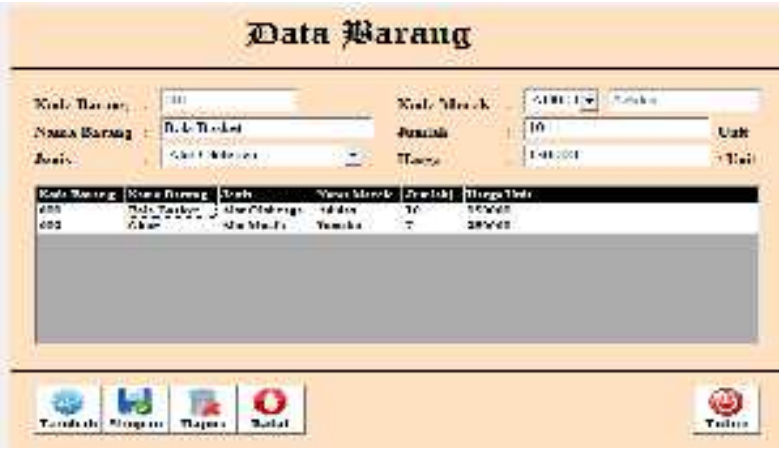

.Gambar 2. Form Barang

\section{Form Karyawan}

Form Karyawan digunakan untuk mengolah data Karyawan, seperti pada gambar 3 berikut :

\section{两ala 戛arpaman}

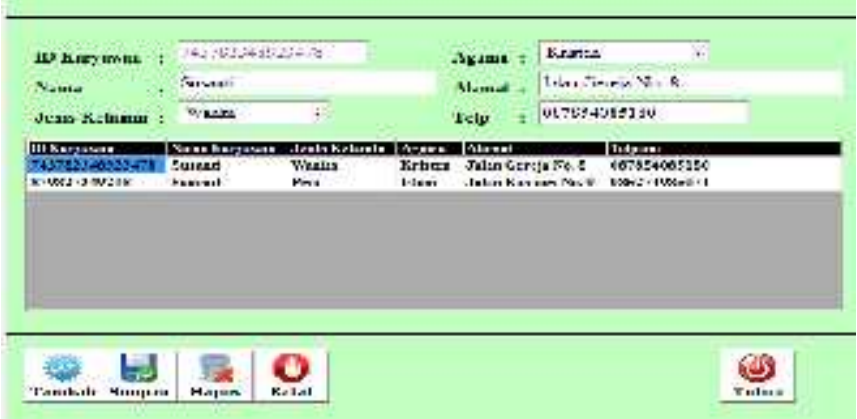

Gambar 3. Form Karyawan

\section{Form Pembeli}

Form Pembeli digunakan untuk mengolah data Pembeli Alat Musik dan Alat Olahraga, seperti pada gambar 4 berikut :

\section{Data Apentuelt}

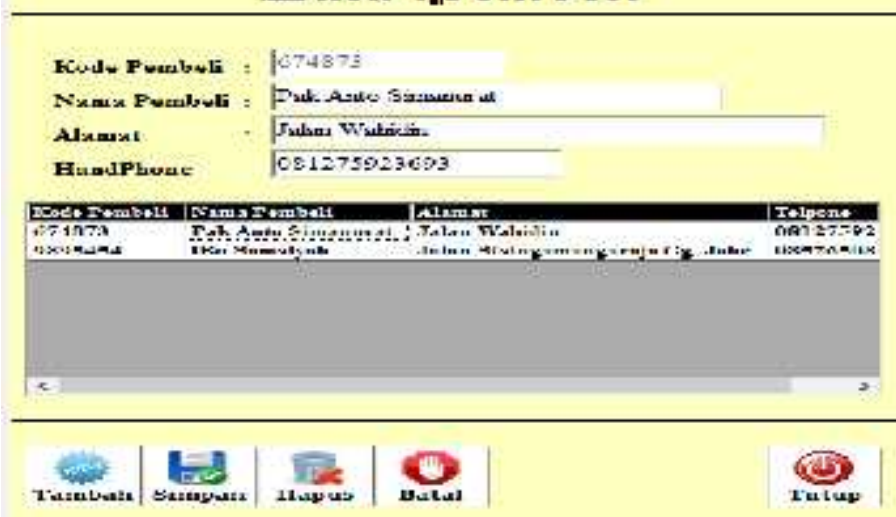

Gambar 4. Form Pembeli

\section{Form Data Transaksi Penjualan}

Form Pembeli digunakan untuk mengolah data Pembeli Alat Musik dan Alat Olahraga, seperti pada gambar 5 berikut : 


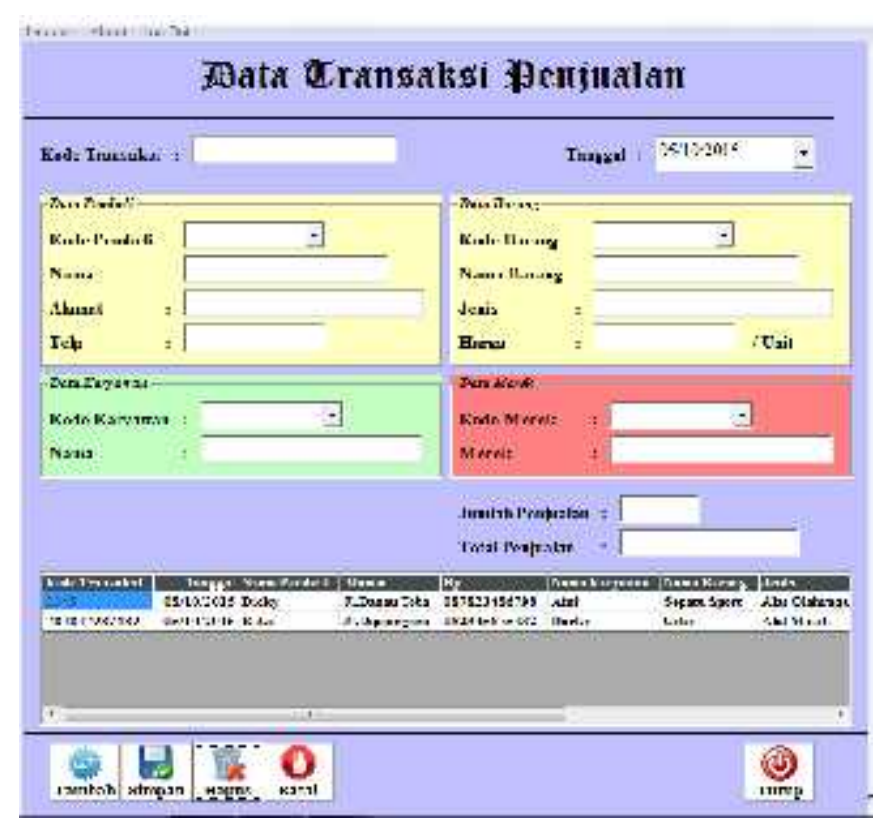

Gambar 5. Form Data TransaksiPenjualan

\section{Form Data Transaksi Penjualan}

Form data transaksi penjualan dapat dilihat seperti pada gambar 6 berikut :

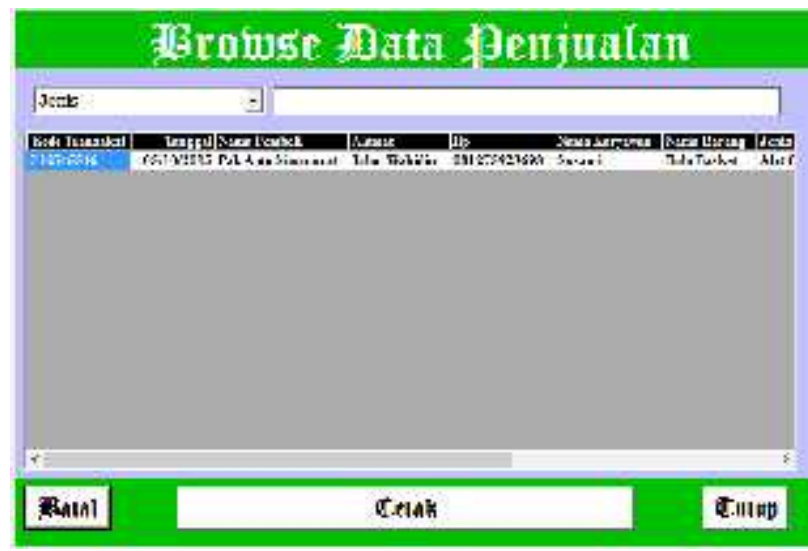

Gambar 6. Form Pencarian Data Penjualan Alat dan Barang Olahraga

\section{Form Laporan Printview Penjualan}

Form laporan Penjualan dapat dilihat seperti pada gambar 7 berikut :

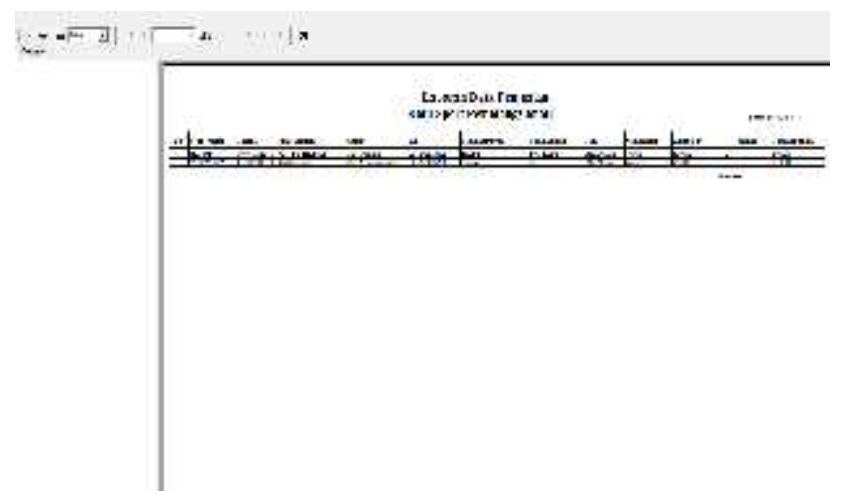

Gambar 7.Tampilan form Laporan Print view Penjualan

\section{SIMPULAN}

Sistem Informasi penjualan alat dan barang olah raga dirancang Menggunakan Microsoft visual basic 6.0. sangat membantu pegawai dalam proses mengolah data penjualan alat dan barang olahraga sehingga sistem penjualan pada toko ratu sport lebih efektif dan efisien.

\section{DAFTAR PUSTAKA}

Handayani, W., Hartama, D., Dewi, R., \& Parlina, I. Aplikasi Pengajuan Beasiswa Berbasis Web. Information systems, 3, 63.

D Hartama, 2001. Microsoft SQL Server. Jakarta: Penerbit Fajar PL3I

Astuti, P. D. (2017). Sistem Informasi Penjualan Obat Pada Apotek Jati Farma Arjosari. SpeedSentra Penelitian Engineering dan Edukasi, 3(4).

Rochmawati, R., \& Valeria, V. (2014). Pengembangan Sistem Informasi Akuntansi Penjualan dan Penerimaan Kas Berbasis Komputer pada Perusahaan Kecil (Studi Kasus pada PT. Trust Technology). Jurnal Bisnis dan Manajemen, 12(1), 17-28.

Parlina, I. (2015). Sistem Informasi Pemesanan Kamar Hotel Sapadia Hotel Pematangsiantar. Proseding Seminar Nasional Rekayasa (SNTR) II

Parlina, I. (2014). Aplikasi Pembayaran Biaya Sertifikat Tanah (Studi Kasus: Kantor Pertanahan Kab. Simalungun). Seminar Nasional Literasi Informasi. 